\title{
BMJ Open Oral drug treatments in patients with erectile dysfunction and multiple comorbidities: a retrospective observational study
}

\author{
Hasniza Zaman Huri, ${ }^{1,2}$ Tee Lian Choo, ${ }^{1}$ Che Zuraini Sulaiman, ${ }^{3}$ Raymond Mark, ${ }^{1}$ \\ Azad Hassan Abdul Razack ${ }^{4}$
}

To cite: Zaman Huri $\mathrm{H}$, Lian Choo T, Sulaiman CZ, et al. Oral drug treatments in patients with erectile dysfunction and multiple comorbidities: a retrospective observational study. BMJ Open 2014;4:e005381. doi:10.1136/bmjopen-2014005381

- Prepublication history and additional material is available. To view please visit the journal (http://dx.doi.org/ 10.1136/bmjopen-2014005381).

Received 2 April 2014 Revised 27 May 2014 Accepted 16 June 2014

\section{CrossMark}

${ }^{1}$ Department of Pharmacy, Faculty of Medicine, University of Malaya, Kuala Lumpur, Malaysia

${ }^{2}$ Clinical Investigation Centre, University Malaya Medical Centre, Kuala Lumpur,

Malaysia

${ }^{3}$ Department of Pharmacy, University of Malaya Medical Centre, Kuala Lumpur, Malaysia

${ }^{4}$ Department of Surgery, Faculty of Medicine, University of Malaya, Kuala Lumpur, Malaysia

Correspondence to Dr Hasniza Zaman Huri; hasnizazh@um.edu.my

\section{ABSTRACT}

Objective: To investigate factors associated with demographic/clinical characteristics and drug selection in patients with erectile dysfunction (ED). The prevalence of $E D$ is increasing worldwide. Studies have shown that ED is associated with age, lifestyle and comorbidities. However, the factors associated with patient characteristics as well as drug selection are incompletely understood.

Setting: A tertiary medical centre in Kuala Lumpur, Malaysia.

Participants: A total of 219 patients (range 2380 years) who had received phosphodiesterase type- 5 (PDE-5) inhibitors as ED treatment were evaluated. Inclusion criteria: Adult patients aged $\geq 18$ years, diagnosed with $E D$, and prescribed with sildenafil, tadalafil or vardenafil.

Exclusion criteria: Patients diagnosed with ED but who did not receive any PDE-5 inhibitor, or those with missing data.

\section{Primary and secondary outcome measures:}

Factors associated with demographic and clinical characteristics as well as drug selection were assessed. Results: Ischaemic heart disease $(p=0.025)$, benign prostatic hyperplasia $(p<0.001)$, obesity $(p=0.005)$, lower urinary tract symptoms (LUTS) $(p=0.006)$ and $\alpha$-blockers $(p<0.001)$ were significantly associated with elderly patients with ED. Additionally, LUTS ( $p=0.038)$ and $\alpha$-blockers $(p=0.008)$ were significantly associated with the selection of PDE-5 inhibitor.

Conclusions: These data showed that elderly patients with ED were significantly associated with comorbidities and $\alpha$-blockers, whereas LUTS and $\alpha$ blockers were associated with drug selection.

\section{INTRODUCTION}

Erectile dysfunction (ED) can be defined as the inability to attain/maintain penile erection sufficiently to undertake sexual intercourse satisfactorily. ${ }^{1}$ ED can more precisely describe this problem than can 'impotence'. The prevalence of ED increases with age, from

\section{Strengths and limitations of this study}

- This article represents utilisation of drug treatment and factors associated with comorbidities and concomitant drugs in patients with erectile dysfunction (ED) with multiple comorbidities. The prevalence of ED is increasing worldwide and research papers from the perspective of pharmaceutical care are currently scarce and limited. This research could provide an insight to healthcare providers specifically and to patients generally. Findings of this study could serve as preliminary data to optimise a pharmaceutical care concept and to ensure quality-use of drug treatments in patients with ED. This could further ensure patients with ED obtain an optimum pharmaceutical care despite having significant numbers of comorbidities. So far, no papers discussing the association of drug treatment with clinical characteristics and comorbidities in patients with ED have been published. This paper could serve as a platform to enhance future studies in an attempt to deliver an optimum pharmaceutical care for patients with ED with multiple comorbidities and finally to promote their quality of life.

- This was a retrospective study in which data availability was highly dependent on medical records. Important information such as erectile function and hormone levels could not be retrieved from such medical records. Also, individual physical factors on the selection of phosphodiesterase type- 5 inhibitors were not considered. Nevertheless, a retrospective design is the most appropriate to assess patient characteristics and selection of drug treatment in patients with ED. Face-to-face interviews would limit a complete data retrieval of patients' clinical comorbidities and drug treatment history.

$6.5 \%$ in men aged $20-29$ years to $77.5 \%$ in men aged $\geq 75$ years. ${ }^{3}$ In Malaysia, the prevalence of $\mathrm{ED}$ in men aged $40-79$ years is $69.5 \%{ }^{4}$ 
ED can have vasculogenic, neurogenic, anatomical, hormonal, drug-induced or psychogenic aetiologies. ${ }^{5}$ Various therapies are available for ED: orally administered phosphodiesterase type-5 (PDE-5) inhibitors, intracavernosal injection of vasoactive agents and transurethral delivery of alprostadil, vacuum constriction devices and penile prostheses. ${ }^{6}$ Testosterone can be given to patients with ED with hypogonadism. ${ }^{7}$

ED is more prevalent in men with comorbidities such as cardiovascular disease (OR 1.45; 95\% CI 1.16 to 1.81 ) and diabetes mellitus (DM; OR 3.13; 95\% CI 2.35 to 4.16). ${ }^{8}$ A community health survey conducted in Boston (Massachusetts, USA) reported that the prevalence of patients with ED with heart disease, DM, hypertension and obesity was $52.3 \%, 49.3 \%, 35.4 \%$ and $23.5 \%$, respectively. ${ }^{9} \mathrm{ED}$ is also associated with lifestyle factors such as physical activity, smoking and alcohol consumption $(\mathrm{p}<0.01) .{ }^{9}$ A cross-sectional survey conducted in Malaysia found that a larger proportion of patients with ED had hypertension (58.7\%), followed by DM (40.9\%), hyperlipidaemia $(35.5 \%)$, obesity $(13.1 \%)$ and heart disease $(8.3 \%)^{4}$

PDE-5 inhibitors such as sildenafil, vardenafil and tadalafil are first-line therapies for ED with proven safety and efficacy. ${ }^{10}$ Various studies showed that PDE-5 inhibitors improve the erectile function in men with comorbidities such as hypertension, DM and hyperlipidaemia. ${ }^{11}$ In 2011, the Food and Drug Administration (FDA) in the USA approved tadalafil as a treatment for the signs and symptoms of benign prostatic hyperplasia (BPH) and ED if both conditions occur simultaneously. ${ }^{12}$ However, there is a risk of hypotension if PDE-5 inhibitors are administered with $\alpha$-blockers. ${ }^{10}$ Hence, factors such as comorbidities and concurrent medication can affect the selection of PDE-5 inhibitors.

Studies on the characteristics of patients with ED and the factors associated with the selection of drug treatment in Malaysia are lacking. We aimed to overcome this hiatus in the present study.

\section{PATIENTS AND METHODS}

\section{Study design and setting}

This was a cross-sectional retrospective study conducted at the University of Malaya Medical Center (UMMC; Malaysia), a teaching hospital with 1000 beds. Approval from the Medical Committee of UMMC (reference number: 956.33) was obtained before the study was carried out.

\section{Study population and sampling frame}

The study involved patients diagnosed with ED with any comorbidity who had received a PDE-5 inhibitor as a treatment option for ED. The sampling frame was from February 2012 to January 2013. The sampling size required was calculated using Epi Info Program ver7.0. The level of significance $(\alpha)$ was set as 0.05 and the desired power of the study $(1-\beta)$ was $80 \%$. Assuming that the expected proportion of patients with ED was
$69.5 \%^{4}$ and the confidence limit $5 \%$, the minimum sample size was calculated to be 139 patients.

\section{Study procedures}

A total of 309 Registration Number $(\mathrm{R} / \mathrm{N})$ patients prescribed with sildenafil, tadalafil or vardenafil from February 2012 to January 2013 were generated from the Pharmacy Information System (PIS). Sampling was conducted to include patients as the study sample. A total of $286(92.6 \%)$ medication records and case notes were retrieved from the Patient Medical Record (PMR) office.

The inclusion criteria were adult patients aged $\geq 18$ years, diagnosed with ED and prescribed with sildenafil, tadalafil or vardenafil. The exclusion criteria were patients diagnosed with ED but who did not receive any PDE-5 inhibitor, or those with missing data.

\section{Data collection}

Data included demographic information (eg, age, ethnicity, height, weight, body mass index (BMI)). Clinical characteristics (eg, duration of ED, smoking, alcohol consumption, comorbidities, medication regimen, laboratory results) were also recorded.

\section{Definitions used in the study}

- 'Comorbidities' were defined as coexisting ailments that required long-term therapy. ${ }^{13}$

- 'Elderly' was defined as patients aged $\geq 65$ years. ${ }^{14}$

- 'Normal weight' was defined as a BMI (in $\mathrm{kg} / \mathrm{m}^{2}$ ) of 18.5-22.9, 'overweight' as 23-27.4 and 'obesity' as $\geq 27.5 .^{15}$

- 'Sudden onset' was defined as the early detumescence of erection during sexual intercourse but maintenance of a normal nocturnal erection. 'Gradual onset' was defined as the slow progression of ED with weakening of erection rigidity. ${ }^{16}$

- 'Pharmacological causes' were defined as the use of medications such as antihypertensive agents that can cause ED. ${ }^{17}$

- 'Psychological causes' were defined as an ability to have an erection in some circumstances but not in others due to performance anxiety, stress or depression. ${ }^{17}$

- 'Medical causes' were defined as ED due to medical conditions such as DM or hypertension. ${ }^{17}$

- 'Surgical causes' were defined as ED due to surgery, irradiation or procedures that involved the prostate gland, bladder, colon, rectum, spinal cord or brain. ${ }^{17}$

- 'Hormonal causes' were defined as ED due to a decrease in serum testosterone levels. ${ }^{17}$

\section{Statistical methods}

All the data collected and extracted were analysed using SPSS ver21 (SPSS, Chicago, Illinois, USA). Normally distributed data were expressed as frequency and mean \pm SD. Non-normally distributed data were expressed as median and IQRs. Categorical data (eg, patient characteristics, comorbidities) were expressed as percentages. The association or correlation of patient characteristics with ED was 
examined using the Pearson $\chi^{2}$ with continuity correction and Fisher's exact test if adjustment was necessary. $p<0.05$ was considered significant. An overview of the study procedure is shown in figure 1 .

\section{RESULTS}

\section{Data collection}

A total of 309 patients were identified from the study population through the PIS. Of these, 286 medical records $(92.6 \%)$ were retrieved from the PMR office. The remainder of the medicals records could not be retrieved from the PMR office. Sixty-seven patients were excluded because they did not fulfil the inclusion criteria, so 219 patients were included.

\section{Demographic and clinical characteristics}

The age of patients did not show a normal distribution (Shapiro-Wilk test; $\mathrm{p}<0.001$ ) (table 1 ). The age range was 23-80 years (median 58 years). The mean body weight was $74.5( \pm 12.8) \mathrm{kg}$ (range 43.9-107.0 kg). Data on clinical characteristics were available for only 122 of 219 patients (55.7\%) for the duration of ED. The median duration of ED was 3 years (range, 6 months to 25 years). Only nine patients $(4.1 \%)$ had information on ED onset.

Figure 2 shows the distribution of concomitant comorbidities in patients with ED. Hypertension, hyperlipidaemia and DM were the most common comorbidities in patients with ED. The other comorbidities were fatty liver disease $(1.8 \%)$, spinal-cord injury (1.8\%), tuberculosis $(1.4 \%)$, atrial fibrillation $(0.9 \%)$, heart failure $(0.5 \%)$, hepatic dysfunction $(0.5 \%)$, renal cell cancer $(0.5 \%)$, colon cancer $(0.5 \%)$, thyrotoxicosis $(0.5 \%)$, chronic hepatitis B $(0.5 \%)$, HIV $(0.5 \%)$, Hashimoto disease $(0.5 \%)$, hypothyroidism $(0.5 \%)$ and systemic lupus erythematosus $(0.5 \%)$.

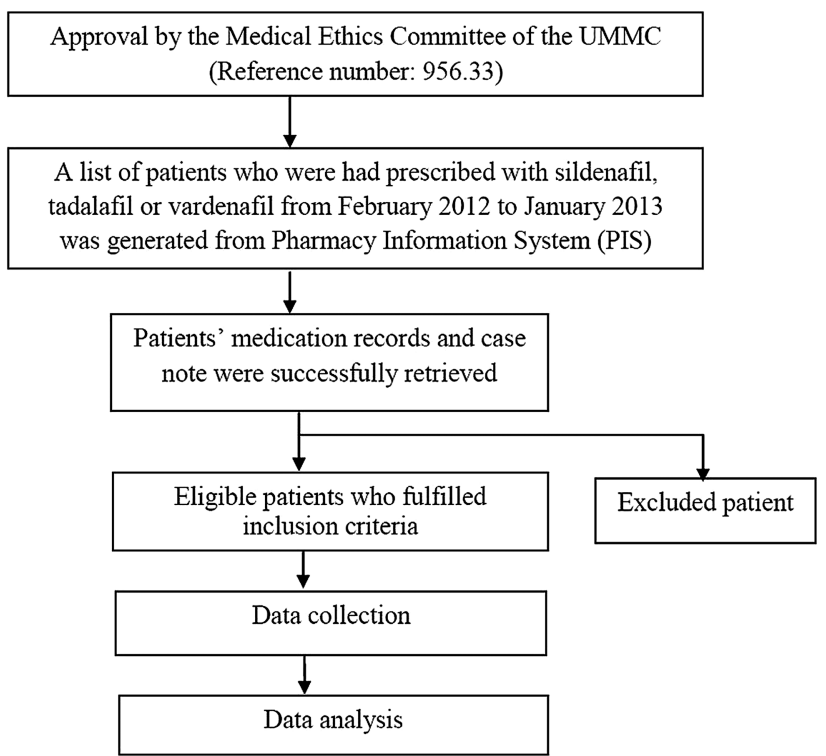

Figure 1 Overview of study procedure.

\section{Concurrent medications}

There was a significant difference between the number of patients with ED who were taking medications commonly used by patients with ED(eg, anti-DM, antihypertensive,

Table 1 Demographic and clinical characteristics of patients with erectile dysfunction

\begin{tabular}{|c|c|c|}
\hline Variables/characteristics & $\begin{array}{l}\text { Number of } \\
\text { patients (\%) }\end{array}$ & p Value \\
\hline Nationality & & $<0.001 \dagger$ \\
\hline Malaysian & $216(98.6)$ & \\
\hline Non-Malaysian & $3(0.4)$ & \\
\hline Ethnicity & & $<0.001 \dagger$ \\
\hline Malay & 69 (31.5) & \\
\hline Chinese & $110(50.2)$ & \\
\hline Indian & $33(15.1)$ & \\
\hline Others & $7(3.2)$ & \\
\hline Age category (years) & & $<0.001 \dagger$ \\
\hline $20-29$ & $3(1.4)$ & \\
\hline 30-39 & $15(6.9)$ & \\
\hline $40-49$ & 27 (12.3) & \\
\hline $50-59$ & $74(33.8)$ & \\
\hline $60-69$ & 64 (29.2) & \\
\hline $70-79$ & $35(16.0)$ & \\
\hline 80 and above & $1(0.4)$ & \\
\hline Mean \pm SD & $57.4 \pm 11.24$ & \\
\hline BMI $\left(\mathrm{kg} / \mathrm{m}^{2}\right)^{\star}$ & & 0.091 \\
\hline Normal body weight & $25(11.4)$ & \\
\hline Overweight & 37 (16.9) & \\
\hline Obese & 43 (19.6) & \\
\hline Unknown & $114(52.1)$ & \\
\hline Cigarettes & & $<0.001 \dagger$ \\
\hline Current smoker & $31(14.1)$ & \\
\hline Ex-smoker & 26 (11.9) & \\
\hline Non-smoker & $76(34.7)$ & \\
\hline Unknown & 86 (39.3) & \\
\hline Alcohol consumption & & $<0.001 \dagger$ \\
\hline Current drinker & 37 (16.9) & \\
\hline Ex-drinker & $3(1.4)$ & \\
\hline Non-drinker & $66(30.1)$ & \\
\hline Unknown & $113(51.6)$ & \\
\hline ED duration (years) $(n=122)$ & & $<0.001 \dagger$ \\
\hline Below 1 year & $7(5.7)$ & \\
\hline $1-4$ & $79(64.8)$ & \\
\hline $5-9$ & $26(21.3)$ & \\
\hline $10-14$ & $6(4.9)$ & \\
\hline $15-19$ & $1(0.8)$ & \\
\hline 20 and above & $3(2.5)$ & \\
\hline Onset $(n=9)$ & & $0.02 \dagger$ \\
\hline Sudden & $1(11.1)$ & \\
\hline Gradual & $8(88.9)$ & \\
\hline $\begin{array}{l}\text { Presence of morning erection } \\
(n=69)\end{array}$ & & $0.001 \dagger$ \\
\hline Yes & 22 (31.9) & \\
\hline No & $36(52.2)$ & \\
\hline Occasionally & $11(15.9)$ & \\
\hline \multicolumn{3}{|c|}{$\begin{array}{l}{ }^{\star} \text { Normal body weight-BMl: } 18.5-22.9 \mathrm{~kg} / \mathrm{m}^{2} ; \text { Overweight-BMl: } \\
23-27.4 \mathrm{~kg} / \mathrm{m}^{2} \text {; obese-BMI } \geq 27.5 \mathrm{~kg} / \mathrm{m}^{2} \text {. } \\
+\chi^{2} \text {, significance level at } \mathrm{p}<0.05 . \\
\text { BMI, body mass index. }\end{array}$} \\
\hline
\end{tabular}




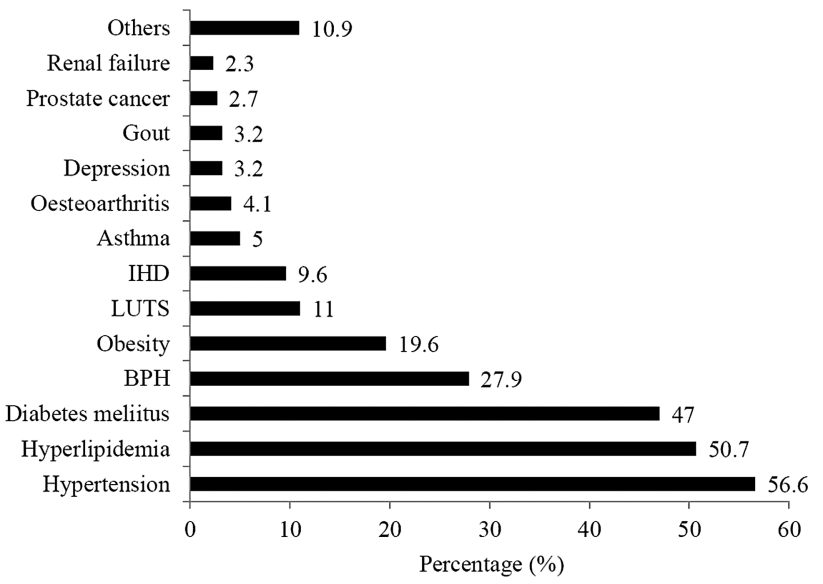

Figure 2 Types of comorbidities in patients with erectile dysfunction (BPH, benign prostatic hyperplasia; IHD, ischaemic heart disease; LUTS, lower urinary tract symptom).

lipid-lowering, antiplatelet, antidepressant) and those who were not $(p<0.001$; table 2$)$. The number of patients with ED who were taking antihypertensive agents $(57.1 \%)$ and lipid-lowering agents (55.7\%) was significantly higher than those who were not on these treatments $(p<0.001)$. The number of patients with ED who used anti-DM agents $(45.2 \%)$, antiplatelet agents $(18.3 \%)$, antidepressants $(4.1 \%)$, bronchodilator agents $(3.7 \%)$ or $\alpha$-blockers $(24.7 \%)$ was significantly less than those who did not take such agents $(\mathrm{p}<0.001)$.

\section{Oral treatments}

Sildenafil was the most commonly $(65.3 \%)$ prescribed PDE-5 inhibitor, followed by tadalafil $(16.9 \%)$ and vardenafil $(17.8 \%)$.

\section{Common comorbidities in patients taking PDE-5 inhibitors}

Hypertension, hyperlipidaemia and DM were the most common comorbidities in patients using sildenafil and tadalafil. For those taking vardenafil, hypertension, hyperlipidaemia and BPH were the most common comorbidities (figure 3).

\section{Factors associated with patient characteristics}

Association of age with comorbidities

Ischaemic heart disease (IHD; $\mathrm{p}=0.025)$, BPH $(\mathrm{p}<0.001)$, obesity $(p=0.005)$ and lower urinary tract symptoms (LUTS; $p=0.006$ ) were associated with elderly patients with ED but other comorbidities were not (table 3 ).

\section{Association of age with medications}

The use of $\alpha$-blockers was significantly associated with elderly patients with ED $(p<0.001)$ but other medications were not (Pearson's $\chi^{2}$ test or Fisher's exact test, table 3).

\section{Factors associated with selection of PDE- 5 inhibitors} Concurrent comorbidities

LUTS were associated with the selection of PDE-5 inhibitors (table 4).
Table 2 Distribution of the patients with ED according to concurrent medications

\begin{tabular}{|c|c|c|}
\hline Medications & $\begin{array}{l}\text { Number of } \\
\text { patients }(\%) \dagger\end{array}$ & p Value* \\
\hline Diabetic agents & & $<0.001$ \\
\hline Oral agents & $74(33.8)$ & \\
\hline Insulin & $6(2.7)$ & \\
\hline Insulin and oral agents & $19(8.7)$ & \\
\hline No & $120(54.8)$ & \\
\hline Antihypertensive agents & & $<0.001$ \\
\hline Yes & $125(57.1)$ & \\
\hline No & 94 (42.9) & \\
\hline Lipid lowering agents & & $<0.001$ \\
\hline Yes & $122(55.7)$ & \\
\hline No & $97(44.3)$ & \\
\hline Antiplatelet agents & & $<0.001$ \\
\hline Yes & $40(18.3)$ & \\
\hline No & $179(81.7)$ & \\
\hline Antidepressants & & $<0.001$ \\
\hline Yes & $9(4.1)$ & \\
\hline No & 210 (95.9) & \\
\hline Bronchodilator agents & & $<0.001$ \\
\hline Yes & $8(3.7)$ & \\
\hline No & 211(96.3) & \\
\hline$\alpha$-Blockers & & $<0.001$ \\
\hline Yes & $54(24.7)$ & \\
\hline No & 165 (75.3) & \\
\hline
\end{tabular}

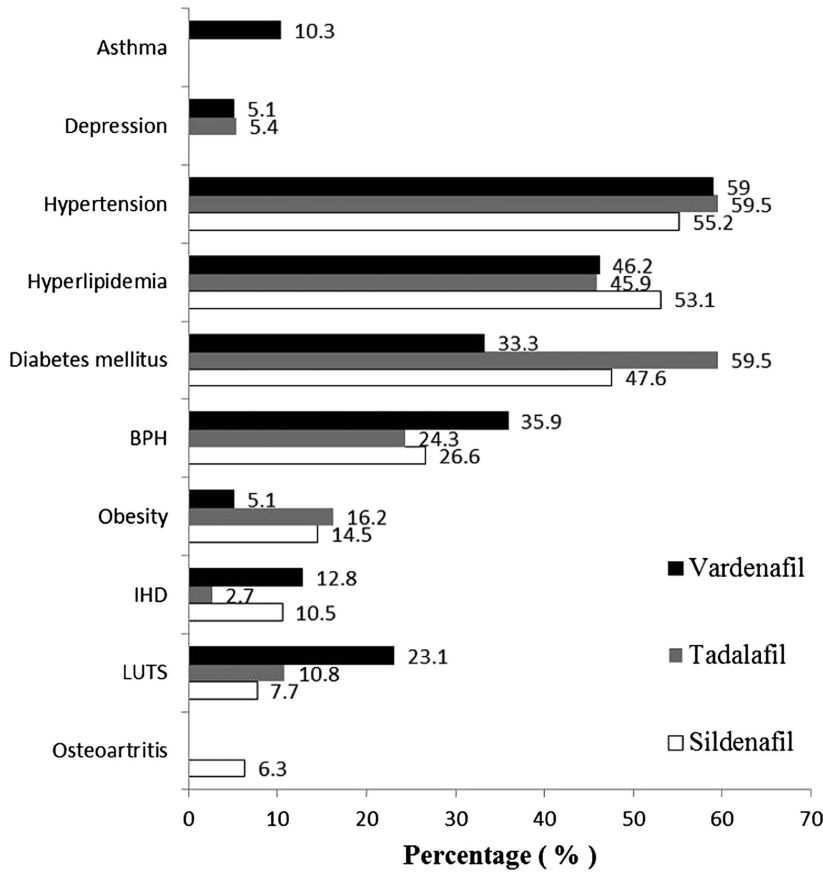

Figure 3 Common comorbidities in patients taking sildenafil $(\mathrm{N}=143)$, tadalafil $(\mathrm{N}=37)$, vardenafil $(\mathrm{N}=39)(\mathrm{BPH}$, benign prostatic hyperplasia; IHD, ischaemic heart disease; LUTS, lower urinary tract symptom). 
Table 3 Association of age (elderly) with types of comorbidities and medications

\begin{tabular}{|c|c|c|c|}
\hline Comorbidities/medication & Elderly & & p Value ${ }^{\star}$ \\
\hline & Yes & No & \\
\hline Hypertension & & & $0.458 \dagger$ \\
\hline Yes & $34(61.8 \%)$ & $90(54.9 \%)$ & \\
\hline No & $21(38.2 \%)$ & $74(45.1 \%)$ & \\
\hline Diabetes mellitus & & & $0.173 \dagger$ \\
\hline Yes & $21(38.2 \%)$ & $82(50.0 \%)$ & \\
\hline No & $34(61.8 \%)$ & $82(50.0 \%)$ & \\
\hline Hyperlipidaemia & & & $0.613+$ \\
\hline Yes & $30(54.5 \%)$ & $81(49.4 \%)$ & \\
\hline No & $25(45.5 \%)$ & $83(50.6 \%)$ & \\
\hline Depression & & & $0.683 \ddagger$ \\
\hline Yes & $1(1.8 \%)$ & $6(3.7 \%)$ & \\
\hline No & $54(98.2 \%)$ & $158(96.3 \%)$ & \\
\hline Ischaemic heart disease & & & $0.025 \dagger$ \\
\hline Yes & $10(18.2 \%)$ & $11(6.7 \%)$ & \\
\hline No & $45(81.8 \%)$ & $153(93.3 \%)$ & \\
\hline Benign prostatic hyperplasia & & & $<0.001 \dagger$ \\
\hline Yes & $43(50.9 \%)$ & $33(20.1 \%)$ & \\
\hline No & $27(49.1 \%)$ & $131(79.9 \%)$ & \\
\hline Obesity & & & $0.005 t$ \\
\hline Yes & $3(13.0 \%)$ & $40(48.8 \%)$ & \\
\hline No & $20(87.0 \%)$ & $42(51.2 \%)$ & \\
\hline LUTS & & & $0.006 \ddagger^{*}$ \\
\hline Yes & $12(21.8 \%)$ & $12(7.3 \%)$ & \\
\hline No & $43(78.2 \%)$ & $152(92.7 \%)$ & \\
\hline No. of comorbidities & & & $0.650 \S$ \\
\hline None & $3(5.5 \%)$ & $23(14.5 \%)$ & \\
\hline One & $9(16.4 \%)$ & $24(14.6 \%)$ & \\
\hline Two & $10(18.2 \%)$ & $33(20.1 \%)$ & \\
\hline Three & $20(36.4 \%)$ & $49(29.9 \%)$ & \\
\hline Four & $12(21.8 \%)$ & $29(17.7 \%)$ & \\
\hline Five & $1(1.8 \%)$ & $5(3.0 \%)$ & \\
\hline Six & $0(0.0 \%)$ & $1(0.6 \%)$ & \\
\hline Diabetic agents & & & $0.054 \S$ \\
\hline Oral agents & $35(63.6 \%)$ & $85(51.8 \%)$ & \\
\hline Insulin & $18(32.7 \%)$ & $56(34.1 \%$ & \\
\hline Insulin and oral agents & $2(3.6 \%)$ & $4(2.4 \%)$ & \\
\hline No & $0(0.0 \%)$ & $19(3.6 \%)$ & \\
\hline Antihypertensive agents & & & $0.595 \dagger$ \\
\hline Yes & $33(61.1 \%)$ & $92(52.8 \%)$ & \\
\hline No & $21(38.9 \%)$ & $73(44.2 \%)$ & \\
\hline Lipid lowering agents & & & $0.502 \dagger$ \\
\hline Yes & $28(50.9 \%)$ & $94(57.3 \%)$ & \\
\hline No & 27 (49.1\%) & $70(42.7 \%)$ & \\
\hline Antiplatelet agents & & & $0.164 \dagger$ \\
\hline Yes & $41(74.5)$ & $138(84.1 \%)$ & \\
\hline No & $12(21.8)$ & $26(15.9 \%)$ & \\
\hline Antidepressants & & & $0.683 \ddagger$ \\
\hline Yes & $54(98.2 \%)$ & 157 (95.7\%) & \\
\hline No & $1(1.8 \%)$ & $7(4.3 \%)$ & \\
\hline Bronchodilator agents & & & $0.867 \dagger$ \\
\hline Yes & $0(0.0 \%)$ & $8(4.9 \%)$ & \\
\hline No & $55(100.0 \%)$ & $156(95.1 \%)$ & \\
\hline$\alpha$-Blockers & & & $<0.001 \dagger^{\star}$ \\
\hline Yes & 28 (51.9) & $26(15.8)$ & \\
\hline No & $26(48.1)$ & $139(84.2)$ & \\
\hline
\end{tabular}

LUTS, lower urinary tract symptom.

${ }^{*} \chi^{2}$, significance level at $p<0.05$.

†Continuity correction.

fFisher's exact test.

$\S$ Pearson's $\chi^{2}$; statistically significant $(p<0.05)$.

Concurrent medications

$\alpha$-Blockers showed a significant association with the selection of oral drugs ( $\mathrm{p}=0.008$, table 4$)$.

\section{DISCUSSION}

We noted a significant association between IHD and elderly patients with ED. In the USA in 2010, the 
Table 4 Association of PDE-5 inhibitors with comorbidities and concurrent medication

\begin{tabular}{|c|c|c|c|c|}
\hline Comorbidities/medications & Sildenafil $(\mathrm{N}=143)$ & $\begin{array}{l}\text { Number of patients (\%) } \\
\text { Tadalafil }(\mathrm{N}=37)\end{array}$ & Vardenafil (N=39) & p Value \\
\hline Hypertension & & & & $0.852 \dagger$ \\
\hline Yes & $79(55.2)$ & $22(59.5)$ & $23(59.0)$ & \\
\hline No & $64(44.8)$ & $15(49.5)$ & $16(41.0)$ & \\
\hline Diabetes mellitus & & & & $0.073 \dagger$ \\
\hline Yes & $68(47.6)$ & $22(59.5)$ & $13(33.3)$ & \\
\hline No & $75(52.4)$ & $15(40.5)$ & $26(66.7)$ & \\
\hline Hyperlipidaemia & & & & $0.607 \dagger$ \\
\hline Yes & $76(53.1)$ & $17(45.9)$ & $18(46.2)$ & \\
\hline No & 67 (46.9) & $20(54.1)$ & $21(53.8)$ & \\
\hline Obesity & & & & $0.795 \dagger$ \\
\hline Yes & $31(39.7)$ & $6(50.0)$ & $6(40.0)$ & \\
\hline No & 47 (60.3) & $6(50.0)$ & $9(60.0)$ & \\
\hline Depression & & & & $0.304 \ddagger$ \\
\hline Yes & $3(2.1)$ & $2(5.4)$ & $2(5.1)$ & \\
\hline No & 140 (97.9) & $35(94.6)$ & 37 (94.9) & \\
\hline IHD & & & & $0.257 \ddagger$ \\
\hline Yes & $15(10.5)$ & $1(2.7)$ & $5(12.8)$ & \\
\hline No & $128(89.5)$ & $36(97.3)$ & $34(87.2)$ & \\
\hline $\mathrm{BPH}$ & & & & $0.449 \dagger$ \\
\hline Yes & $38(26.6)$ & $9(24.3)$ & $14(35.9)$ & \\
\hline No & $105(73.4)$ & $28(75.7)$ & $25(64.1)$ & \\
\hline LUTS & & & & $0.038 \mp$ \\
\hline Yes & $11(7.7)$ & $4(10.8)$ & $9(23.1)$ & \\
\hline No & $132(92.3)$ & 33 (89.2) & 30 (76.9) & \\
\hline Diabetic agents & & & & $0.084 \dagger$ \\
\hline Oral agents & $52(36.4)$ & $15(40.5)$ & 17 (17.9) & \\
\hline Insulin & $3(2.1)$ & $0(0.0)$ & $3(7.7)$ & \\
\hline Insulin and oral agents & $11(7.7)$ & $5(13.5)$ & $3(7.7)$ & \\
\hline No & $77(53.8)$ & $17(45.9)$ & $26(66.7)$ & \\
\hline Antihypertensive agents & & & & $0.417 \dagger$ \\
\hline Yes & $91(63.6)$ & $23(62.2)$ & $29(74.4)$ & \\
\hline No & $52(36.4)$ & $14(37.8)$ & $10(25.6)$ & \\
\hline Lipid lowering agents & & & & $0.477 \dagger$ \\
\hline Yes & $78(54.5)$ & $19(51.4)$ & $25(64.1)$ & \\
\hline No & $65(45.5)$ & $18(48.6)$ & $14(35.9)$ & \\
\hline Antiplatelet agents & & & & $0.413 \dagger$ \\
\hline Yes & $29(20.3)$ & $4(10.8)$ & 7 (17.9) & \\
\hline No & $114(79.7)$ & $33(89.2)$ & $32(82.1)$ & \\
\hline Antidepressants & & & & $0.120 \ddagger$ \\
\hline Yes & $3(2.1)$ & $2(5.4)$ & $3(7.7)$ & \\
\hline No & $140(97.9)$ & $35(94.6)$ & $36(92.3)$ & \\
\hline Bronchodilator agents & & & & $0.120 \ddagger$ \\
\hline Yes & $3(2.1)$ & $2(5.4)$ & $3(7.7)$ & \\
\hline No & 140 (97.9) & $35(94.6)$ & 36 (92.3) & \\
\hline$\alpha$-Blockers & & & & $0.008 \dagger$ \\
\hline Yes & $31(21.7)$ & $17(43.6)$ & 6 (16.2) & \\
\hline No & $112(78.3)$ & $22(56.4)$ & 31 (83.8) & \\
\hline
\end{tabular}

*Statistically significant $(p<0.05)$.

†Computed using Pearson's $\chi^{2}$.

¥Computed using Fisher's exact test.

$\mathrm{BPH}$, benign prostatic hyperplasia; IHD, ischaemic heart disease; LUTS, lower urinary tract symptom.

prevalence of IHD in elderly patients was reported to be $19.8 \% .^{18}$ In Malaysia in 2006, IHD was the second leading cause of death $(15.5 \%$ of individuals who died in government hospitals). ${ }^{19}$ The Men's Attitudes to Life Events and Sexuality (MALES) study (27 839 participants) found that men with IHD had a higher prevalence of ED. ${ }^{20}$ Endothelial dysfunction causes a reduction in the level of nitric oxide (NO), which is responsible for muscle relaxation in the penis, and might be the mechanism that links IHD and ED. ${ }^{21}$ The 
arterial size hypothesis is based on an association between ED and chronic heart disease. ${ }^{22}$ This hypothesis suggests that obstruction of the penile artery precedes obstruction of the coronary artery. ${ }^{22}$ If so, ED can be used to predict the risk of IHD (one retrospective study showed that ED appeared first in $71 \%$ of patients). ${ }^{23}$ Hence, elderly patients with IHD should be aware of the risk of ED.

There was a significant association between BPH and being an elderly patient with ED $(p<0.001)$. In Malaysia, the prevalence of BPH is $>50 \%$ in men aged $\geq 60$ years. ${ }^{24} \mathrm{BPH}$ is usually associated with a series of LUTS, including nocturia, increased urinary hesitancy, frequency and urgency, as well as a weak dribbling stream of urine and increased postvoiding residual volumes. $^{25}$

Several studies have indicated that BPH with associated LUTS increased incidence of ED. ${ }^{20} 26$

Medications used in BPH treatment may affect normal erectile function. ${ }^{21}$ The contradictory facts of improving versus disrupting erectile function were not well understood; however, at least one study has shown that the use of $\alpha$-blockers may cause ED. ${ }^{27}$ The use of $5 \alpha$ - reductase inhibitors has been associated with decreased erectile function due to low levels of $\mathrm{NO}$ and thus related to a decline in dihydrotestosterone levels. ${ }^{28}$ Other than drugs, surgery for treatment of ED may also affect erectile function. For instance, one of the long-term complications of transurethral resection of the prostate (TURP) in patients with BPH is ED. One study found that $12 \%$ of patients with ED underwent TURP for BPH. ${ }^{29}$ Thus, elderly patients with BPH should be aware of the risk of ED.

Being elderly and having ED was found to be associated with obesity $(p=0.005)$. According to the Third National Health and Morbidity Survey, the prevalence of overweight and obesity in elderly patients in Malaysia is $29.2 \% .^{30}$ Another study conducted in the rural area of Selangor in Malaysia found that the prevalence of obesity in patients aged $\geq 60$ years was $9.3 \% .^{31}$ In the Health Professionals Follow-up Study (22086 participants in the USA), obesity was found to increase the risk of ED compared with an ideal BMI (relative risk 1.9; CI 1.6 to 2.2$){ }^{32}$ Several mechanisms could link ED with obesity. First, visceral obesity induces an inflammatory response that can lead to endothelial dysfunction. ${ }^{33}$ Second, obesity and associated comorbidities such as the metabolic syndrome can cause a lower level of testosterone in plasma that can lead to hypogonadism. ${ }^{33}$ This hypothesis is supported by a study involving 2435 men with ED which found that obesity was associated with lower levels of testosterone in the body. ${ }^{34}$ Conversely, one study showed that physical activity and weight reduction improved erectile function in one-third of obese men with ED. ${ }^{35}$ Thus, obesity is a modifiable risk factor that can prevent or improve the outcome of ED.

LUTS were commonly present in elderly patients with ED. One study in a tertiary hospital in Malaysia found that the prevalence of moderate-to-severe LUTS was $42.7 \%$ in men aged $\geq 40$ years. ${ }^{36}$ Several studies have established the relationship between ED and LUTS. For example, a local population-based survey found that men with moderate and severe LUTS had a 1.4-times increased risk of getting ED. ${ }^{37} \mathrm{~A}$ prospective study conducted in five Asian countries involving 916 patients reported ED in $80 \%$ of patients with LUTS. ${ }^{38}$ That study also found a reduction of International Index of Erectile Function (IIEF)-5 scores with increasing age. ${ }^{38}$ Also, a survey conducted in the USA and six European countries found that $90 \%$ of 12815 patients had LUTS, and that $83 \%$ of patients were sexually active. ${ }^{39}$ Nevertheless, ED was present in almost half of the patients who had LUTS. ${ }^{39}$ A possible explanation for this association is a reduction in NO levels in the penis and prostate muscle. ${ }^{40}$ Hence, because of evidence showing an association between LUTS and ED, elderly patients should be assessed for sexual function during LUTS management.

Only $\alpha$-blockers were significantly associated with elderly patients with ED. $\alpha$-Blockers are used mainly for $\mathrm{BPH}$ treatment or as adjunct therapy if blood pressure is not well controlled. ${ }^{31}{ }^{42}$ In Malaysia, the prevalence of $\mathrm{BPH}$ is $>50 \%$ in men aged $>60$ years. ${ }^{24} \alpha$-Blockers such as tamsulosin used in BPH have been found to have a negative impact on erectile function ${ }^{27}$ but alfuzosin has been reported to have a positive impact on erectile function in experimental models. ${ }^{43}$ Thus, caution with the use of $\alpha$-blockers in elderly patients with ED is needed.

There was a significant association between LUTS and drug selection. Evidence-based guidelines on the selection of PDE-5 inhibitors in patients with ED with different comorbidities are lacking. The distribution of LUTS was higher for vardenafil, followed by tadalafil and sildenafil. One study in animals investigating the efficacy of PDE-5 inhibitors for LUTS treatment found that, compared with tadalafil and sildenafil, vardenafil was the most potent drug for the relaxation of prostate and urethral tissue. ${ }^{44}$ Additionally, we previously found that vardenafil and tadalafil could inhibit proliferation of stromal cells in the prostate gland and hence prevent enlargement of the prostate gland. ${ }^{44}$ Tadalafil is the only drug approved by the FDA for treatment of the signs and symptoms of BPH (specifically known as LUTS). ${ }^{12}$ This could be the reason behind the greater usage of vardenafil and tadalafil in patients with LUTS: they can be used for the treatment for ED and LUTS. Patients who took $5 \mathrm{mg}$ of tadalafil reported a significant improvement in symptoms of ED and BPH. ${ }^{45}$

There was a significant association between the $\alpha$-blockers and the type of PDE- 5 inhibitor. The combined treatment can promote an improvement in both psychometric parameters of voiding dysfunction (namely, International Prostate Symptom Score (IPSS) scores) and ED (namely, IIEF-EF), and a significant amelioration of the $\mathrm{Q}_{\max }{ }^{46} 47$

The distribution was higher in tadalafil, followed by sildenafil and vardenafil. Tadalafil has been shown to elicit 
the least significant reduction in blood pressure when taken with a uroselective or non-uroselective $\alpha$-blocker. ${ }^{48}$ In contrast, a greater reduction in blood pressure has been noted if sildenafil is given together with an $\alpha$-blocker. ${ }^{49}$ The combination of vardenafil and an $\alpha$-blocker resulted in an increased prevalence of hypotension compared with the placebo group in one study ${ }^{50}$ This could be the reason behind the higher usage of tadalafil with the $\alpha$-blocker in the present study.

\section{CONCLUSION}

ED was prevalent in men aged $\geq 50$ years. Patients with ED often had comorbidities such as hypertension, DM and hyperlipidaemia. IHD, BPH, obesity and LUTS were associated with elderly patients with ED. Thus, elderly patients with these diseases should be aware of the risk of ED. The presence of LUTS and $\alpha$-blockers was significantly associated with the selection of PDE- 5 inhibitor. Hence, further studies on the combinations of $\alpha$-blockers and PDE-5 inhibitors are required to develop more effective pharmacological management of LUTS and ED.

Contributors $\mathrm{HZH}$ and AHAR have made substantial contributions to the conception and design of the study. HZH has been involved in acquisition of data, analysis and interpretation of data and drafting of the manuscript or revising it critically for important intellectual content. TLC, CZS and RM have been involved in acquisition of data and analysis and interpretation. HZH, TLC, CZS, RM and AHAR have given final approval to the version to be published.

Funding The authors would like to thank the Ministry of Science, Technology and Innovation, Malaysia (Science fund: 12-02-03-2097) and University of Malaya, Malaysia (University of Malaya Research Grant: RG428/12HTM) for financial and technical support.

Competing interests None.

Ethics approval Medical Ethics Committee, University of Malaya Medical Centre.

Provenance and peer review Not commissioned; externally peer reviewed.

Data sharing statement No additional data are available.

Open Access This is an Open Access article distributed in accordance with the Creative Commons Attribution Non Commercial (CC BY-NC 4.0) license, which permits others to distribute, remix, adapt, build upon this work noncommercially, and license their derivative works on different terms, provided the original work is properly cited and the use is non-commercial. See: http:// creativecommons.org/licenses/by-nc/4.0/

\section{REFERENCES}

1. National Institutes of Health. Consensus statement on impotence. Int $J$ Impot Res 1992;10:1-33.

2. Lizza EF, Rosen RC. Definition and classification of erectile dysfunction: report of the Nomenclature Committee of the International Society of the International Society of Impotence Research. Int J Impot Res 1999;11:141.

3. Saigal CS, Wessells $\mathrm{H}$, Pace $\mathrm{J}$, et al. Predictors and prevalance of erectile dysfunction in a racially diverse population. Arch Inter Med 2006;166:207-12

4. Ab Rahman AA, Al-Sada N, Low WY. Prevalence of erectile dysfunction in primary care setting, Malaysia. J Mens Health 2011;8: S50-3.

5. Wespes E, Amar E, Hatzichristou D, et al. EAU Guidelines on erectile dysfunction: an update. Eur Urol 2006;49:806-15.

6. Montague DK, Jarow JP, Broderick GA, et al. Chapter 1: The management of erectile dysfunction: an AUA update. J Urol $2005 ; 174: 230-9$
7. Shabsigh R. Hypogonadism and erectile dysfunction: the role of testosterone therapy. Int J Impot Res 2003;15(S4):S9-13.

8. Grover SA, Lowensteyn L, Kaouache M, et al. The prevalence of erectile dysfunction in the primary care setting: importance of risk factors for diabetes and vascular disease. Arch Inter Med 2006;166:213-19.

9. Kupelian V, Araujo AB, Chiu GR, et al. Relative contributions of modifiable risk factors to erectile dysfunction: results from the Boston Area Community Health (BACH) Survey. Prevent Med 2010;50:19-25.

10. Hatzimouratidis K, Amat E, Eardley I, et al. (2010) Guidelines on male sexual dysfunction: erectile dysfunction and premature ejaculation. Eur Urol 2010;57:804-14.

11. Nehra A. Erectile dysfunction and cardiovascular disease: efficacy and safety of phosphodiesterase type 5 inhibitors in men with both conditions. Mayo Clin Proc 2009;84:139-48.

12. Food and Drug Administration. FDA new release: FDA approves Cialis to treat benign prostatic hyperplasia. 2011.

13. Valderas JM, Starfield B, Sibbald B, et al. Defining comorbidity: implications for understanding health services. Ann Fam Med 2009;7:354-63.

14. World Health Organization (WHO). Definition of an older or elderly person from 2012. Revised 18 Feb 2013. http://www.who.int/ healthinfo/survey/ageingdefnolder/en/

15. Ministry Of Health of Malaysia. Clinical practise guidelines on management of obesity. 2004.

16. Lutra A, Misra A. Erectile dysfunction in diabetic males: Plausible mechanism and management strategies. Diabetes Metab Syndr Clin Res Rev 2008;1:81-6.

17. Safarinejad MR, Hosseini SY. Erectile dysfunction: Clinical guidelines (1). Urol J 2004;1:133-47.

18. Fang J, Shaw KM, Keenan NL. Prevalence of coronary heart disease-United States, 2006-2010. Morbid Mortal Wkly Rep 2011;60:1377-411.

19. Cruez AF. Rise in heart disease a worry. New Straits Times, 2008.

20. Rosen RC, Altwein J, Boyle P, et al. Lower urinary tract symptoms and male sexual dysfunction: the multinational survey of the aging male (MSAM-7). Eur Urol 2003;44:637-49.

21. Rosen RC, Giuliano F, Carson C. Sexual dysfunction and lower tract symptoms (LUTS) associated with benign prostatic hyperplasia (BPH). Eur Urol 2005;47:824-37.

22. Montorsi P, Ravagnani PM, Galli S, et al. The artery size hypothesis: a macrovascular link between erectile dysfunction and coronary artery disease. Am J Cardiol 2005;96:19-23.

23. Montorsi P, Ravagnani PM, Galli S, et al. (2006) Association between erectile dysfunction and coronary artery disease. Role of coronary clinical presentation and extent of vessel involvement: the COBRA trial. Eur Heart J 2006;27:2632-9.

24. Ministry Of Health of Malaysia. Medical management of symptomatic benign prostatic hyperplasia. Health Technology Assessment Unit Medical Development Division. Ministry of Health, 2002.

25. Zaman Huri H, Hui Xin C, Sulaiman CZ. Drug-related problems in patients with benign prostatic hyperplasia: a cross sectional retrospective study. PLOS ONE 2014;9:e86215.

26. Braun M, Wassmer G, Klotz T, et al. Epidemiology of erectile dysfunction: results of the 'Cologne Male Survey'. Int J Impot Res 2000;12:305-11.

27. Song $\mathrm{SH}$, Son $\mathrm{H}$, Kim KT, et al. Effect of tamsulosin on ejaculatory function in BPH/LUTS. Asian J Androl 2011;13:846-50.

28. Erdemir F, et al. 5-Alpha reductase inhibitors and erectile dysfunction: the connection. J Sex Med I 2008:5:2917-24.

29. Poulakis V, Ferakis N, Witzsch U, et al. Erectile dysfunction after transurethral prostatectomy for lower urinary tract symptoms: results from a center with over 500 patients. Asian J Androl 2006;8:69-74.

30. Suzana S, Kee CC, Jamaludin AR, et al. The Third National Health and Morbidity Survey: Ppevalence of obesity, and abdominal obesity among the Malaysian elderly population. Asia Pac J Public Health 2012;24:318-29.

31. Yunus AM, Sherina MS, Nor Afiah MZ, et al. Prevalence of cardiovascular risk factors in a rural community in Mukim Dengkil, Selangor. Malays J Nutr 2004;10:5-11.

32. Bacon CG, Mittleman MA, Kawachi I, et al. A prospective study of risk factors for erectile dysfunction. J Urol 2006;176:217-21.

33. Traish AM, Feely RJ, Guay A. Mechanisms of obesity and related pathologies: androgen deficiency and endothelial dysfunction may be the link between obesity and erectile dysfunction. FEBS $J$ 2009;276:5755-67.

34. Corona G, Mannucci E, Fisher AD, et al. Low levels of androgens in men with erectile and obesity. J Sex Med 2008;5:2454-63.

35. Esposito K, Giugliano F, Di Palo C, et al. Effect of lifestyle changes on erectile dysfunction in obese men: a randomized controlled trial. JAMA 2004;291:2978-84. 
36. Ho CCK, Praveen S, Goh EH, et al. Prevalence and awareness of lower urinary tract symptoms among males in the outpatient clinics of Universiti Kebangsaan Malaysia Medical Centre. Med Health 2011;6:98-106.

37. Mariappan P, Wooi LC. Prevalence and correlations of lower urinary tract symptoms, erectile dysfunction and incontinence in men from a multiethnic Asian population: results of a regional population-based survey and comparison with industrialized nations. BJU Int 2006:98:1264-8.

38. Li MK, Garcia LA, Patron N, et al. An Asian multinational prospective observational registry of patients with benign prostatic hyperplasia, with a focus on comorbidities, lower urinary tract symptoms and sexual function. BJU Int 2007;101:197-202.

39. Rosen RC, Fisher WA, Eardley I, et al. The multinational Men's Attitudes to Life Events and Sexuality (MALES) study: prevalence of health concerns in the general population. Curr Med Res Opin 2004;20:607-17.

40. Li MK, Garcia LA, Rosen R. Lower urinary tract symptoms and male sexual dysfunction in Asia: a survey of ageing men from five Asian countries. BJU Int/ 2005;96:1339-54.

41. American Urological Association. American Urological Association guideline: management of benign prostatic hyperplasia $(B P H)$. American Urological Association Education and Research, Inc., 2010.

42. Ministry of Health Malaysia: Management of hypertension, 3rd edition. Clinical Practice Guideline. 2008.

43. Carson CC. Combination of phosphodiesterase- 5 inhibitors and alpha blockers in patients with benign prostatic hyperplasia: treatments of lower urinary tract symptoms, erectile dysfunction, or both? BJU Int 2006;97:39-43.
44. Tinel H, Stelte LB, Hutter J, et al. Pre-clinical evidence for the use of phosphodiesterase- 5 inhibitors for treating benign prostatic hyperplasia and lower urinary tract symptoms. BJU Int 2006;98:1259-63.

45. Egerdie RB, Auerbach S, Roehrborn CG, et al. Tadalafil 2.5 or $5 \mathrm{mg}$ administered once daily for 12 weeks in men with both erectile dysfunction and signs and symptoms of benign prostatic hyperplasia: results of a randomized, placebo-controlled, double-blind study. J Sex Med 2012;9:271-81.

46. Liguori G, Trombetta C, De Giorgi G, et al. Efficacy and safety of combined oral therapy with tadalafil and alfuzosin: an integrated approach to the management of patients with lower urinary tract symptoms and erectile dysfunction. Preliminary report. J Sex Med 2009;6:544-52.

47. Gacci M, Corona G, Salvi M, et al. A systematic review and meta-analysis on the use of phosphodiesterase 5 inhibitors alone or in combination with $\alpha$-blockers for lower urinary tract symptoms due to benign prostatic hyperplasia. Eur Urol 2012;61:994-1003.

48. Guillaume M, Lonsdale F, Darstein C, et al. Hemodynamic interaction between a daily dosed phosphodiesterase 5 inhibitor, tadalafil, and the $\alpha$-adrenergic blockers, doxazosin and tamsulosin in middle-aged healthy male subjects. J Clin Pharmacol 2007:47:1303-10.

49. Pfizer. VIAGRA (sildenafil citrate) prescribing information from 2010. Revised 23 February 2013. http://www.pfizer.com/files/products/ uspi_viagra.pdf

50. Bayer Health Care Pharmaceuticals. Product monograph for LEVITRA (vardenafil HCL), 2011. Revised 2 March 2013. http:// www.univgraph.com/bayer/inserts/levitra.pdf 